\title{
COVID-19 pandemic: Mechanistic approaches and gender vulnerabilities
}

\author{
Luqman Khan ${ }^{a}$, Nisar Ul Khaliq ${ }^{b}$, Asad Ullah ${ }^{\text {a }}$, Naseem Rafiq ${ }^{c}$, Mujib Ullah ${ }^{\mathrm{d}, *}$ \\ a School of Medicine, University of California, San Francisco, CA 94158, USA \\ ${ }^{\mathrm{b}}$ Department of Industrial and Physical Pharmacy, Purdue University, West Lafayette, IN 47907, USA \\ ${ }^{\mathrm{c}}$ Department of Zoology, Abdul Wali Khan University, Mardan, KPK, Pakistan \\ ${ }^{\mathrm{d}}$ Department of Immunology and Transplantation, School of Medicine, Stanford University, CA, USA
}

\section{A R T I C L E I N F O}

\section{Article history:}

Received 8 September 2020

Accepted 23 November 2020

Available online 25 November 2020

\section{Keywords:}

COVID-19

Gender Vulnerability

Mortality

Pandemic

\begin{abstract}
A B S T R A C T
Severe Acute Respiratory Syndrome Coronavirus 2 (SARS-CoV-2) is a highly pathogenic virus that causes coronavirus-19 disease (COVID-19), a severe respiratory damaging syndrome with serious health complications worldwide. SARS-CoV-2 was unfamilar before the epidemic started in Wuhan, China, in December 2019. COVID-19 is currently a pandemic influencing several countries worldwide. One of the mysteries of the new coronavirus is that it is deadlier for men than women with the male mortality rate is twice as high as that of females.

(c) 2020 Published by Elsevier B.V. on behalf of King Saud University. This is an open access article under the CC BY-NC-ND license (http://creativecommons.org/licenses/by-nc-nd/4.0/).
\end{abstract}

\section{Summary}

Since its emergence in Wuhan, a city in Hubei province of China, COVID-19 has provoked widespread infectivity around the globe. According to Global Health 5050, a society that encourages gender-specific similarities in health care (Sharma, Volgman, \& Michos, 2020; Sohrabi et al., 2020) male populations infected with the 2019 novel coronavirus-19 (COVID-19) are prone to more acute infections following deaths as compared to females (Xie, Tong, Guan, Du, \& Qiu, 2020). The report suggested a role of sex biology in humans' risk of infectivity and death as a consequence of COVID 19.

CoV-19 attaches to the body's immune cells, triggering the antibody reaction in both COVID 19-infected and non-symptomatic individuals. Typically, males produce fewer robust immune responses than females and are highly prone to a selection of contagious means (Conti \& Younes, 2020; Klein \& Flanagan, 2016). Several reports propose variances between males and females in their immune reaction to communicable and inflammatory ill-

\footnotetext{
* Corresponding author.

E-mail address: ullah@stanford.edu (M. Ullah).

Peer review under responsibility of King Saud University.
}

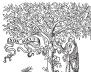

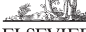

\section{Production and hosting by Elsevier}

nesses like TB, malaria, hepatitis, HIV-1, mumps, measles, and flu (Rettew, Huet-Hudson, \& Marriott, 2008).

Females are functional tesselations for $\mathrm{X}$-lined genes that are related to immunity hence qualify them to incite stronger innate and adaptive immune responses resulting in low infectivity (Fung, Huang, \& Liu, 2014). Structural changes in the host cells due to virus overload may also contribute to the high infectivity in male (Schurz et al., 2019). A recent study has revealed the role gender plays in morbidity and mortality of SARS-CoV-2 infection (Drosten et al., 2003). Studies pondering the mechanistic aspect for infectivity suggest that males have high concentration of circulating angiotensin-converting enzyme 2 (ACE2) than in their female counterpart (Patel, Velkoska, \& Burrell, 2013; Ullah, 2020a). ACE2 is the targeting receptor site for the (SARS-CoV) and the associated human respiratory coronavirus NL63, that exhibit in human airway epithelia and lung parenchyma (Jia et al., 2005). High-throughput sequencing has shown that (SARS-CoV-

2) looks like (SARS-CoV) (Jia et al., 2005).

Severe acute respiratory syndrome coronavirus preferentially attack the (ACE2) receptors due to sequencing similarity. Hence, males are more likely to be affected by (SARS-CoV-2) in contrast to females. Researchers sequenced the genome of the virus and established numerous auspicious vaccine candidates for experimental testing (Grifoni et al., 2020). The recovered antibodies from COVID-19 individuals might be considered to treat persons with initial signs and stop the spread of infection (Casadevall and Pirofski, 2020; Jin et al., 2020; Wu et al., 2020).

The role of transmembrane protease serine 2 (TMPRSS2) in coronavirus infections, and modulation of COVID-19 severity is still 
unknown (Cheng et al., 2015). Some reports suggest its involvement in influenza severity in humans and animals (Cheng et al., 2015). TMPRSS2 (testosterone regulated gene) is higher in men than women. However, TMPRSS2 expression levels and their role are also regulated by estrogen-dependent signaling (Cheng et al., 2015; Penna, Mercurio, Tocchetti, \& Pagliaro, 2020; Sakai et al., 2015).

The higher mortality of COVID-19 in men may be due to sexspecific responses, as the immune cells obtained from women usually show a greater response compared to those isolated from men (Scotland, Stables, Madalli, Watson, \& Gilroy, 2011). Male has lower basal immunoglobulin levels and a smaller number of circulating and resident CD4/CD8 T-lymphocytes ratio than females (Amadori et al., 1995; Li, Jerkic, Slutsky, \& Zhang, 2020).

So far, no vaccine has been approved by the Food and Drug Administration (FDA) for COVID-19 treatment. However, some potential drugs have been reported which might help to reduce the severity of COVID-19. Upon intravenous or subcutaneous administration of Tocilizumab helps in reducing the mortality as well as the risk of invasive mechanical ventilator in severe COVID-19 (Guaraldi et al., 2020).

Angiotensin receptor blockers (ARBs) have effects that are parallel to angiotensin converting enzyme (ACE) inhibitors, however ACE inhibitors act by inhibiting the development of angiotensin II instead of blocking the binding of angiotensin II to muscles on blood vessels (Jia et al., 2005; Ullah, 2020b). ARBs are used for regulating high blood pressure, to treat heart failure, and restrain kidney failure in individuals with diabetes (Ullah, 2020a; Xie et al., 2020). Hence, angiotensin receptor blockers (ARBs such as losartan, valsartan, telmisartan, etc.) can be a novel therapeutic approach to block the binding and therefore, attachment of SARS-CoV-2 RBD to ACE2-expressing cells, thus inhibiting their infection to the host cells.

Apart from antivirals, immunotherapeutic strategies have been proposed with emphasis on the immune response of the host defense against the virus, and the fact that SARS-CoV-2 suppresses interferon induction as an immune evasion approach (Drosten et al., 2003; Ullah, 2020a). Active immunization via vaccines, interferon administration, passive immunotherapy by convalescent plasma or synthesized monoclonal and polyclonal antibodies, as well as immunomodulatory drugs, are different immunotherapeutic approaches against the (SARS-CoV-2) (Owji, Negahdaripour, \& Hajighahramani, 2020; Ullah, 2020b). Some of these vaccines are in advanced human clinical trials. Convalescent plasma therapy is already exercised in several countries to help save the lives of severely ill patients (Sharun et al., 2020). Diverse antibodies that target several phases of SARS-CoV-2 pathogenesis or the related immune responses are also suggested. To treat the cytokine storm, induced at a later stage of the disease in some patients, immune modulation through JAK inhibitors, corticosteroids, and other cognate classes are assessed (Owji et al., 2020).

\section{Conclusion}

The sex and gender discrepancies seen in COVID-19 vulnerability underline the need to comprehend the influence of sex and gender on prevalence and case mortality of the disease and to modify treatment conferring to sex and gender. Understanding from previous outbreaks and pandemics has shown the significance of integrating sex and gender evaluation into preparation and response efforts for health interventions. These differences may be due to known sex differences in genes, chromosomes, and hormones that lead to very different responses to many diseases, including COVID-19.
There is a dire need to establish develop efficient platforms that can develop effective vaccines and antiviral medicines robustly for such outbreaks. Globally, health systems and drugs manufacturing companies have been progressing sluggishly compared to speedy pathogens partly due to technical, political, and investment barriers.

\section{Funding}

Not Applicable.

Availability of data and materials

Not Applicable.

Ethics approval and consent to participate

Not Applicable.

Consent for publication

The article and the sources used have been cited in the article.

\section{CRediT authorship contribution statement}

Luqman Khan: Conceptualization, Writing - review \& editing. Nisar Ul Khaliq: Writing - review \& editing. Asad Ullah: Writing - review \& editing. Naseem Rafiq: Writing - review \& editing. Mujib Ullah: Writing - review \& editing.

\section{Declaration of Competing Interest}

The authors declare that they have no known competing financial interests or personal relationships that could have appeared to influence the work reported in this paper.

\section{References}

Amadori, A., Zamarchi, R., De Silvestro, G., Forza, G., Cavatton, G., Danieli, G.A., Chieco-Bianchi, L., 1995. Genetic control of the CD4/CD8 T-cell ratio in humans. Nat. Med. 1 (12), 1279-1283.

Casadevall, A., \& Pirofski, L. March 2020, posting date. The convalescent sera option for containing COVID-19. J Clin Invest https://doi. org/10.1172/JCI138003.

Cheng, Z., Zhou, J., To, K.K.-W., Chu, H., Li, C., Wang, D., Bossé, Y., 2015. Identification of TMPRSS2 as a susceptibility gene for severe 2009 pandemic A (H1N1) influenza and A (H7N9) influenza. J. Infect. Dis. 212 (8), 1214-1221.

Conti, P., Younes, A., 2020. Coronavirus COV-19/SARS-CoV-2 affects women less than men: clinical response to viral infection. J. Biol. Regul. Homeost Agents 34 (2), 71 .

Drosten, C., Günther, S., Preiser, W., Van Der Werf, S., Brodt, H.-R., Becker, S., Fouchier, R.A., 2003. Identification of a novel coronavirus in patients with severe acute respiratory syndrome. N. Engl. J. Med. 348 (20), 1967-1976.

Fung, T.S., Huang, M., Liu, D.X., 2014. Coronavirus-induced ER stress response and its involvement in regulation of coronavirus-host interactions. Virus Res. 194, $110-123$.

Grifoni, A., Sidney, J., Zhang, Y., Scheuermann, R. H., Peters, B., \& Sette, A. (2020). A sequence homology and bioinformatic approach can predict candidate targets for immune responses to SARS-CoV-2. Cell host \& microbe.

Guaraldi, G., Meschiari, M., Cozzi-Lepri, A., Milic, J., Tonelli, R., Menozzi, M., Borghi, V., 2020. Tocilizumab in patients with severe COVID-19: a retrospective cohort study. The Lancet Rheumatology 2 (8), e474-e484.

Jia, H.P. Look, D.C. Shi, L., Hickey, M., Pewe, L., Netland, J., McCray, P.B., 2005. ACE2 receptor expression and severe acute respiratory syndrome coronavirus infection depend on differentiation of human airway epithelia. J. Virol. 79 (23), 14614-14621.

Jin, J.-M., Bai, P., He, W., Wu, F., Liu, X.-F., Han, D.-M., Yang, J.-K., 2020. Gender differences in patients with COVID-19: Focus on severity and mortality. Front. Public Health 8, 152.

Klein, S.L., Flanagan, K.L., 2016. Sex differences in immune responses. Nat. Rev. Immunol. 16 (10), 626.

Li, Y., Jerkic, M., Slutsky, A.S., Zhang, H., 2020. Molecular mechanisms of sex bias differences in COVID-19 mortality. Crit. Care 24 (1), 1-6.

Owji, H., Negahdaripour, M., Hajighahramani, N., 2020. Immunotherapeutic approaches to curtail COVID-19. Int. Immunopharmacology 106924.

Patel, S.K., Velkoska, E., Burrell, L.M., 2013. Emerging markers in cardiovascular disease: Where does angiotensin-converting enzyme 2 fit in?. Clin. Exp. Pharmacol. Physiol. 40 (8), 551-559.

Penna, C., Mercurio, V., Tocchetti, C.G., Pagliaro, P., 2020. Sex-related differences in COVID-19 lethality. Br. J. Pharmacol. 177 (19), 4375-4385.

Rettew, J.A., Huet-Hudson, Y.M., Marriott, I., 2008. Testosterone reduces macrophage expression in the mouse of toll-like receptor 4 , a trigger for inflammation and innate immunity. Biol. Reprod. 78 (3), 432-437. 
Sakai, K., Sekizuka, T., Ami, Y., Nakajima, N., Kitazawa, M., Sato, Y., Komase, K., 2015. A mutant H3N2 influenza virus uses an alternative activation mechanism in TMPRSS2 knockout mice by loss of an oligosaccharide in the hemagglutinin stalk region. J. Virol. 89 (9), 5154-5158.

Schurz, H., Salie, M., Tromp, G., Hoal, E.G., Kinnear, C.J., Möller, M., 2019. The X chromosome and sex-specific effects in infectious disease susceptibility. Human genomics 13 (1), 2.

Scotland, R.S., Stables, M.J., Madalli, S., Watson, P., Gilroy, D.W., 2011. Sex differences in resident immune cell phenotype underlie more efficient acute inflammatory responses in female mice blood. J. Am. Soc. Hematology 118 (22), 5918-5927.

Sharma, G., Volgman, A.S., Michos, E.D., 2020. Sex differences in mortality from COVID-19 pandemic: are men vulnerable and women protected?. Case Reports 2 (9), 1407-1410.

Sharun, K., Tiwari, R., Iqbal Yatoo, M., Patel, S.K., Natesan, S., Dhama, J., Dhama, K., 2020. Antibody-based immunotherapeutics and use of convalescent plasma to counter COVID-19: advances and prospects. Expert Opin. Biol. Ther. 20 (9), 1033-1046.

Sohrabi, C., Alsafi, Z., O’Neill, N., Khan, M., Kerwan, A., Al-Jabir, A., Agha, R., 2020. World Health Organization declares global emergency: A review of the 2019 novel coronavirus (COVID-19). International Journal of Surgery.

Ullah, M., 2020a. Novel Coronavirus (COVID-19) Treatment Options. Biomed J. Sci. $\begin{array}{llll}\text { Tech. Res. (BJSTR) } 27 & \text { (3), 20872-20874. https://doi.org/10.26717/ }\end{array}$ BJSTR.2020.27.004518.

Ullah, M., 2020b. The Pandemic of Novel Coronavirus Disease 2019 (COVID-19): Need for an Immediate Action. Open Access J. Biomed. Sci. 2 (1). https://doi.org/ 10.38125/oajbs.000168.

Wu, A., Peng, Y., Huang, B., Ding, X., Wang, X., Niu, P., . . W Wang, J. (2020). Genome composition and divergence of the novel coronavirus (2019-nCoV) originating in China. Cell host \& microbe.

Xie, J., Tong, Z., Guan, X., Du, B., Qiu, H., 2020. Clinical characteristics of patients who died of coronavirus disease 2019 in China. JAMA network open 3 (4). e205619-e205619. 